which may be causative in this high level of primary school violence.

\section{FALLING TVS: IS IT A RESOLVED PROBLEM?}

${ }^{1} \mathrm{~V}$ Pietrantonio, ${ }^{1} \mathrm{~L}$ Omizzolo, ${ }^{2} \mathrm{R}$ Snenghi, ${ }^{1} \mathrm{~A}$ Spagna, ${ }^{2} \mathrm{R}$ El Mazloum, ${ }^{1} \mathrm{G}$ Vettore, ${ }^{1} \mathrm{~S}$ Vigolo, ${ }^{2} \mathrm{RM}$ Gaudio, ${ }^{1} \mathrm{P}$ Feltracco, ${ }^{1} \underline{\mathrm{S} \text { Barbieri. }}{ }^{1}$ Dipartimento Urgenza Emergenza Padova; ${ }^{2}$ Dipartimento Medicina Legale Padova

\subsection{6/injuryprev-2016-042156.921}

Introduction A growing number of injuries and deaths from televisions falling from furniture are reported in literature although these are completely preventable injuries. Such injuries are ideal for a public education campaign targeting parents, health care workers, and television manufacturers.

Methods We report 2 cases of trauma sustained from falling TV arrived to our Emergency Department.

Results In these 2 cases there are no adult witnesses to the event, but they were alerted by a loud crashing sound of a falling TV. The death incidents occurred because TVs were on surfaces not suitable for TVs, a bookcase in the first case, and in the second case on a small table. The Glasgow Coma Scale score on admission was 3 , in the first case and 8 in the second.

The first baby, 2 years old, reported major traumatic brain injuries, and the impact force resulted in severe trauma and death. CT results revealed extended fracture parietal-occipital. In the second case the baby was playing with the TV's electrical cords and remained blocked under the product resulting in crushing and compressing injuries: the entire dresser and television fell over and the television landed on the boy's head.

Discussion The kind of trauma sustained from a falling TV depends on the length of time the victim has been trapped under the TV, on the impact force, on the point where the victims were hit on the age, and on the weight and size of the TV.

Conclusion As the incidents resulted from the instability of the furniture on which the TVs were set and that the same TV's were not properly anchored and could fall onto the victims, it is to be noted that they can be prevented by simply anchoring TVs and furniture.

Televisions should only be placed on furniture designed to hold them, such as stands or media centres or they should be anchored to the wall. Items that might tempt kids to climb should also be removed, such as toys and remote controls, from the top of the TV and furniture.

\section{CHILD RESTRAINT USE IN THE STATE OF QATAR: FINDINGS FROM AN OBSERVATIONAL STUDY}

${ }^{1}$ Rafael Consunji, ${ }^{2}$ Katharine A Allen ${ }^{2}$ Ruben Peralta, ${ }^{2}$ Rania Abdelhamid, ${ }^{2}$ Shahnaz Malik, ${ }^{1}$ Amber Mehmood, 'Adnan A Hyder. 'Johns Hopkins School of Public Health, Baltimore, USA; ${ }^{2}$ Hamad Medical Corporation, Doha, Qatar

\subsection{6/injuryprev-2016-042156.922}

Background Properly used child restraints have been shown to reduce serious death and road traffic injuries to children under 5 years by 80 to $90 \%$. Yet such use remains low around the world. In Qatar, a high-income developing country, child restraint use is not mandated by law even though road traffic injuries are a leading cause of death for $0-5$ year olds. This study aimed to assess the extent of child restraint use, among children under 5 years, in Qatar.
Methods A roadside observational study was conducted outside of 9 nurseries and 3 shopping malls in Qatar. Trained observers observed vehicles over a 10 - day period and completed 240 hours of observations collecting data on estimated age of child, restraint use and type at nursery and mall entrances.

Results 2,232 vehicle observations were captured from May-June 2015. Over half of all children were either unrestrained $(38 \%)$ or restrained improperly (21\%). Only $27 \%$ of vehicle drivers were unrestrained or improperly restrained. For children less than 5 years old and seated in a rear seat, $28 \%$ were unrestrained while $8 \%$ were improperly wearing an adult seatbelt. Eleven percent of children were incorrectly located in the front passenger seat, unrestrained and/or on an adult's lap.

Conclusions Child restraint use among under-5s is low in Qatar even while the majority of adult drivers use seatbelts. Given that road traffic injuries are a leading cause of death for children aged 0-5 in Qatar, efforts should be focused on increasing their appropriate use. As a high-income country where much of the population with children is able to afford restraints, interventions should be developed to increase child passenger safety. This should include the enforcement of the current law banning children under 10 years from riding in the front seat, the passage and enforcement of a national law mandating child restraint use, and educational campaigns to increase parental awareness of the benefits of child restraints.

\section{ROAD TRAFFIC INJURIES BY ROAD USER TYPE AMONG CHILDREN AND ADOLESCENTS BETWEEN 1990 AND 2013}

1,2Uzma Rahim Khan, 'Mathilde Sengoelge, ${ }^{2}$ Nukhba Zia, 2,3Junaid Abdul Razzak, ${ }^{1}$ Marie Hasselberg, ${ }^{1,4}$ Lucie Laflamme. ${ }^{1}$ Karolinska Institutet, Sweden; ${ }^{2}$ Aga Khan University, Pakistan; ${ }^{3}$ Johns Hopkins University School of Medicine, Maryland; ${ }^{4}$ University of South Africa, South Africa

\subsection{6/injuryprev-2016-042156.923}

Background In 2010 more than half of road traffic injury (RTI) deaths occurred to pedestrians, bicyclists and motorcyclists defined as vulnerable road users (VRUs). Lower middle income countries account for the highest proportion of VRU deaths. The distribution of RTI burden by road user type in children globally, regionally and by income levels is unclear. To investigate countrylevel changes over time in global child RTI deaths among VRUs and non-VRUs with respect to region, economy between 1990 and 2013

Methods Country-level data were extracted from the Global Burden of Disease study, split into seven geographical regions and four income levels (low-income [LICs], lower-middle [LMICs], upper-middle [UMICs] and high-income [HICs]). Death rates and percent change in rates between 1990 and 2013 were calculated for road users aggregated, and independently for VRUs and non-VRUs.

Results Child RTI death rates decreased globally, by region and across all country economic categories between 1990 and 2013 (a global average of 32\% reduction in RTI death rates from 1990 to 2013 and a range of $28 \%$ (LICs) $-54 \%$ (HICs). Reductions were also found for both VRUs (35\%) and non-VRUs (25\%) except in LICs where a $16 \%$ increase arose among non-VRUs. This applies particularly to those LICs from South Asia (26\%). Death rates of VRUs (35\%) in the LMICs of Sub -Saharan Africa also reported increments. For VRUs, the decrease was more than twice higher in HICs (58\%) and LICs (44\%) compared to UMICs $(20 \%)$ or LMICs $(23 \%)$. 
Conclusions The distribution of RTI death varies across different economic categories and regions of the world by road user type.

\section{FACTORS ASSOCIATED WITH CYBERBULLY VICTIMISATION AMONG SECONDARY SCHOOL ADOLESCENTS IN OYO STATE, NIGERIA}

Adesola Olumide, Emmanuel Adebayo. University of Ibadan, Nigeria

\subsection{6/injuryprev-2016-042156.924}

Background Cyberbullying, described as, “a form of aggression involving the use of information and communication technology to post or send harassing or embarrassing messages to another person", is an emerging global problem. This study presents findings on the prevalence and factors associated with cyberbully victimisation among secondary school adolescents in Oyo state, Nigeria.

Methods A cross-sectional study that utilised a multi-stage sampling technique to select 653 students from schools within the state was conducted. Information on students' socio-demographic characteristics and history of cyberbullying in the three-month preceding the study was obtained from the students.

Results The respondents' mean age was $14.2 \pm 2.2$ years and $51.3 \%$ were females. About $50.7 \%$ of all respondents were in senior secondary classes and $50.5 \%$ had internet access. Two hundred and sixty (39.8\%) had been victims of cyberbullying and 94.3\% experienced cyberbullying after school hours. Respondents were often harassed through phone calls (53.2\%), in chat rooms $(25.2 \%)$ and through websites (0.4\%). Fifty-two percent of victims reported the incident. Of these $52.7 \%$ informed a friend, $28.7 \%$ informed a parent/guardian and $1.6 \%$ their class teacher. Factors associated with cyberbully victimisation were the respondents' gender (females more than males), older age, access to internet and being in a senior class. Multiple logistic regression analysis revealed that students with internet access had a higher odds of being victims of cyberbullying $(\mathrm{OR}=2.5, \mathrm{CI}$ : $=1.7-$ 3.6). Respondents in senior classes also had a higher odds of being victims of cyberbullying $(\mathrm{OR}=1.7, \mathrm{CI}:=1.1-2.6)$.

Conclusions The prevalence of cyberbully victimisation was high and students with internet access and those in senior classes were more likely to be victims. Interventions to prevent cyberbullying and improve reporting by victims need to be instituted in schools in the study area in order to curb the problem.

\section{SAFETY OF BABIES, CHILDREN AND YOUTH}

Gregoria Paixão Von Amann, Ines Silva, Joana Azevedo. Directorate General of Health, Ministry of Health; , MAPFRE Foundation, DOREL Industries, Sandra Nascimento, Portuguese Association for Child Safety Promotion, Portugal

\subsection{6/injuryprev-2016-042156.925}

Background Despite the large reduction of child mortality due to traffic collisions, safe and secure transportation of children from birth and through the life cycle, it continues being a concern of the Ministry of Health and the Ministry of Internal Affairs. For this common problem they join effort and under the auspicious of the Decade of Action of Road Safety, on 11 may 2011 launched a project aimed to improve safe transport of newborns since they leave Hospital maternity and along childhood.

Methods The National Road Safety Strategy reinforce strategic and operational objectives and the National Program of Injury
Prevention develops a project called Safety of Babies, Children and Youth targets of reducing child mortality and serious injury and to increase the use of child restraint systems.

For the implementation of the project we have a partnership with DOREL, a company that produces in Portugal child restraint systems and MAPFRE Foundation who developed a website on child road safety supports costs from training health professional and production of booklets and leaflets. The Portuguese Association for Child Safety Promotion, an NGO working in child safety give us their expertise in child restrains system and is also a partner of the project.

Results Currently we have 47 projects implemented in Hospital Maternity and Health Centres across the country, 6000 health professional involved and 60000 parents trained on how to use and use properly child restraints system. In the near future we will start working with the grandparents.

Conclusions The successful implementation of the project in the health services mobilised other actors that spontaneously joined us and are already engaged in community important aspects like control of the use of safety devices near schools and kindergartens by police forces and it's beginning a taxi drivers movement called 'taxis children's friends'.

\section{SCHOOL TRAVEL MODE OF CHILDREN IN URBAN LOW INCOME CITY, KARACHI, PAKISTAN}

1,2Uzma Rahim Khan, 2,3Junaid Abdul Razzak, 'Marie Hasselberg, 1,4Lucie Laflamme. ${ }^{1}$ Karolinska Institute, Sweden; ${ }^{2}$ Aga Khan University, Pakistan; ${ }^{3}$ Johns Hopkins University School of Medicine, Maryland; ${ }^{4}$ University of South Africa, South Africa

\subsection{6/injuryprev-2016-042156.926}

Background Children are more likely to be accompanied by the age 10 after which their independent mobility increases initially as pedestrian and bicyclists, and later as drivers of motorcycles and four-wheelers. The mobility patterns of children were mostly surveyed in high or upper middle income countries. The aim of this study was to understand the mobility in children to and from school in urban dense lower middle income country.

Methods This survey of school children was conducted from September to December 2014 in Karachi, Pakistan. Children in grades $6-10$ approximately age $10-14$ years from a random sample of 58 schools were interviewed face to face and their parents were interviewed on telephones. Mobility pattern was compared across gender.

Results There were 1288 children and 732 parents interviewed. On the day of survey, majority of children reported walking $(72 \%)$ to schools $(58.6 \%$ girls' vs $41.4 \%$ boys). Majority of parents $(71 \%)$ also reported walking as the travel model of children to and from school. There were $22 \%$ boys who came to school on their own compared to $16 \%$ girls however more girls $(30 \%)$ were accompanied with someone compared to boys (5.4\%). While according to parents $49 \%$ of boy children and $29 \%$ of girl children were allowed to go school on their own. Less than half $(43 \%)$ of children were allowed to cross main roads (same ratio of boys and girls). There were three-fourth girls who thought their parents never trust them when they were in road traffic on their own.

Conclusions Although walking is the common travel mode of both boys and girls for their schools but parents' license for mobility varies by sex of the children with more restrictions for girls. 